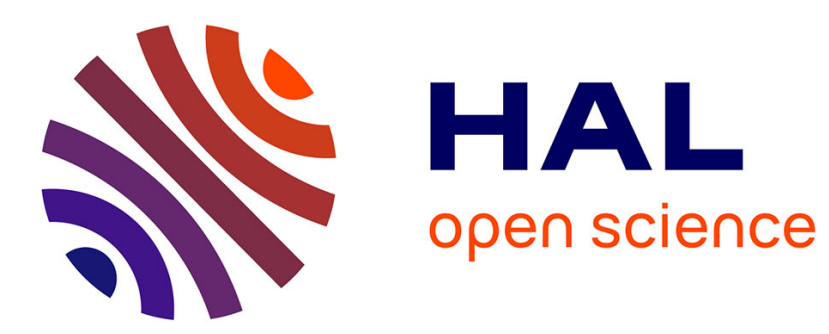

\title{
Determination of anchoring energies from surface tilt angle measurements in a nematic liquid crystal
}

\author{
D. Rivière, Yves Levy, E. Guyon
}

\section{To cite this version:}

D. Rivière, Yves Levy, E. Guyon. Determination of anchoring energies from surface tilt angle measurements in a nematic liquid crystal. Journal de Physique Lettres, 1979, 40 (10), pp.215-218. 10.1051/jphyslet:019790040010021500 . jpa-00231610

\section{HAL Id: jpa-00231610 https://hal.science/jpa-00231610}

Submitted on 1 Jan 1979

HAL is a multi-disciplinary open access archive for the deposit and dissemination of scientific research documents, whether they are published or not. The documents may come from teaching and research institutions in France or abroad, or from public or private research centers.
L'archive ouverte pluridisciplinaire HAL, est destinée au dépôt et à la diffusion de documents scientifiques de niveau recherche, publiés ou non, émanant des établissements d'enseignement et de recherche français ou étrangers, des laboratoires publics ou privés. 


\title{
Determination of anchoring energies from surface tilt angle measurements in a nematic liquid crystal (*)
}

\author{
D. Rivière, Y. Lévy \\ Laboratoire d'Expériences Fondamentales en Optique, Institut d'Optique Théorique et Appliquée, \\ Bât. 503, Université de Paris-Sud, 91406 Orsay, France
}

and E. Guyon

Laboratoire de Physique des Solides, Bât. 510, Université de Paris-Sud, 91405 Orsay, France

(Reçu le 26 février 1979, accepté le 29 mars 1979)

\begin{abstract}
Résumé. - En mesurant de manière précise l'orientation des molécules d'un cristal liquide nématique au voisinage d'un substrat, il est possible d'évaluer l'énergie d'ancrage. L'équilibre des forces superficielles et des forces élastiques détermine la structure géométrique de la distorsion. Pour un film de SiO évaporé obliquement, on trouve une énergie voisine de $10^{-3} \mathrm{erg} / \mathrm{cm}^{2}$.
\end{abstract}

\begin{abstract}
The anchoring energy of a nematic liquid crystal can be evaluated from measurements of the tilt angle at the boundary of its substrate. The equilibrium between surface and elastic energies determines the geometric structure of the distortion. For an obliquely evaporated SiO film, the energy value is about $10^{-3} \mathrm{erg} / \mathrm{cm}^{2}$.
\end{abstract}

In previous articles [1], [2], we have shown that it is possible to determine liquid crystal tilt angles at the boundary of a substrate with great accuracy ; we have also suggested the possibility of evaluating the anchoring energy. The purpose of this paper is to explain the theory of this effect and to give some experimental results.

1. Theoretical considerations. - Consider a liquid crystal cell composed of two parallel glass plates separated by spacers of different thickness so as to form a small wedge (Fig. 1). With no external field, the equilibrium state is determined only by the elasticity of the nematic material and the anchoring at the boundary surfaces. From the elastic continuum theory of liquid crystals [3], [4], we can write the free energy density :

$$
F=\frac{1}{2} K(\nabla \theta)^{2}
$$

(we assume the one-constant approximation : $K=K_{11}=K_{22}=K_{33}$, where $K_{11}, K_{22}$ and $K_{33}$ represent the elastic constants corresponding to splay,

(*) First reported at the 7th International Liquid Crystal Conference (Bordeaux, July 1978).

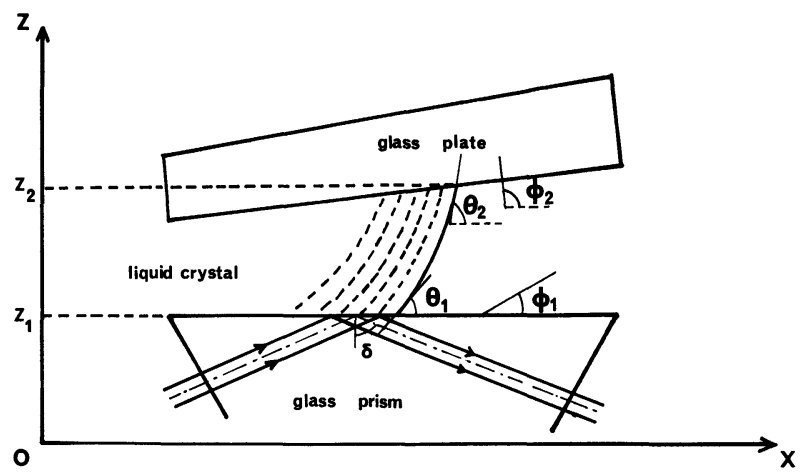

Fig. 1. - Liquid crystal cell forming a small wedge $: \varphi_{1}$ and $\varphi_{2}$ represent the easy axis of the molecules; $\theta_{1}$ and $\theta_{2}$ are the real tilt angles at the boundary surfaces.

twist and bend distortions). The Euler-Lagrange equation for minimization of the total bulk energy is Laplace's equation :

$$
\nabla^{2} \theta=0 .
$$

If we assume that the rotation of the director is confined to the $x O z$ plane, integration of (2) yields :

$$
\theta=a z+\theta_{0}
$$


where $a$ is a constant representative of the bulk distortion in the nematic material (splay and bend).

The balance of forces leads to the conditions :

$$
\left(\frac{\mathrm{d} W_{\mathrm{si}}}{\mathrm{d} \theta}\right)=K\left(\frac{\partial \theta}{\partial z}\right)_{z=z_{i}}
$$

where $i=(1 ; 2) ; W_{\mathrm{s} i}$ is the energy corresponding to the liquid crystal orientation in the vicinity of the surface for $z=z_{i}$. This energy, which is required to move the molecules by a small angle from their equilibrium position $\varphi_{i}$, can be expressed by the formula (5) :

$$
W_{s i}=W_{i} \sin ^{2}\left(\theta-\varphi_{i}\right) .
$$

where $W_{i}$ is then the anchoring energy relative to the boundary surface. The results of equation (5) may be admissible if we assume strong anchoring and small tilt angle variations around the equilibrium position. We shall see later the self-consistency of these assumptions. Now, we can write from (4) and (5):

$$
K a=2 W_{i} \sin \left(\theta_{i}-\varphi_{i}\right) \cos \left(\theta_{i}-\varphi_{i}\right)
$$

or

$$
K a \simeq 2 W_{i}\left(\theta_{i}-\varphi_{i}\right) .
$$

The last expression leads to :

$$
W_{i}=\frac{K a}{2\left(\theta_{i}-\varphi_{i}\right)}
$$

To evaluate $a$ in our experiment we can write :

$$
a=\frac{\theta_{1}-\theta_{2}}{d} \simeq \frac{\varphi_{1}-\varphi_{2}}{d}=\frac{\Delta \varphi}{d} .
$$

where $d$ is the cell thickness.

The final result is :

$$
W_{1}=\frac{K \Delta \varphi}{2 d\left(\theta_{1}-\varphi_{1}\right)}
$$

2. Experimental results. - To perform our experiments, a liquid crystal cell is constructed of a glass prism of high refractive index $(N \sim 1.9)$ and a parallel glass plate separated by teflon spacers (Fig. 1); the upper plate is treated with a surfactant (organosilane) to obtain good homeotropic alignment of the nematic material $\left(\varphi_{2}=90^{\circ}\right.$ and $\left.\theta_{2} \sim 90^{\circ}\right)$. Such an interface presents a strong liquid crystal orienting interaction [6], the anchoring energy being approximately $10^{-2} \mathrm{erg} / \mathrm{cm}^{2}$ [7]. The prism hypotenuse is coated with a thin $\mathrm{SiO}$ film. We used two consecutive oblique evaporations [8], [9] : the first $\mathrm{SiO}$ film is evaporated at oblique incidence $\left(\psi_{1} \sim 70^{\circ}\right)$ and the second one at grazing incidence $\left(\psi_{2} \sim 85^{\circ}\right)$, the total thickness being about $350 \AA$. Such a coating gives us a tilt of the director $\left(\varphi_{1} \sim 30^{\circ}\right)$. The liquid crýstal is 4-cyano-4'-nhexylbiphenyl (6 CB) and the measurements were performed at constant temperature :

$$
T=18.0 \pm 0.2^{\circ} \mathrm{C} \text {. }
$$

For the tilt angle determination, we use the experimental device used in the previous experiments [1], [2] and shown in outline in figure 2 : for a parallel polarization (TM), the critical angle depends on the orientation of the nematic liquid crystal, considered as a uniaxial anisotropic medium. We have proved [2] that this measurement involves a very thin boundary layer at the substrate, the thickness of which is approximately the penetration depth of the evanescent wave in the anisotropic medium (several $\mu \mathrm{m}$ ). In our experiment, the laser beam diameter is about $1 \mathrm{~mm}$, and we assume a constant nematic thickness over this diameter (the wedge angle formed with spacers of different thickness is $18^{\prime}$ of arc). The measurements of the distance $x$ provide an evaluation of $d(x)$ corresponding to the tilt angle $\theta_{1}(x)$. For each value of $d(x)$ we have measured the reflectivity $R_{\|}$(parallel polarization) as a function of the incidence angle $\delta$ and deduced from it the tilt angle $\theta_{1}(x)$. The results are given in figure 3. To determine the tilt angle, it is appropriate to take the value of incidence corresponding to :

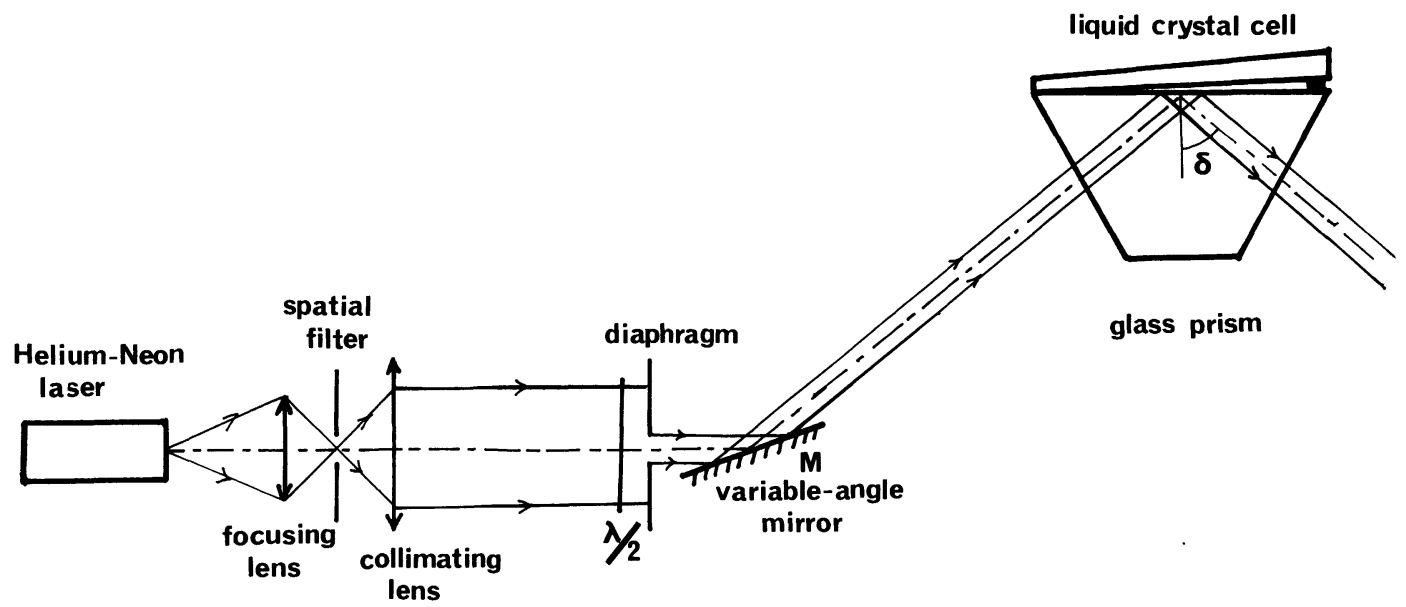

Fig. 2. - Experimental arrangement used to determine nematic liquid crystal tilt angle in the vicinity of a substrate. 


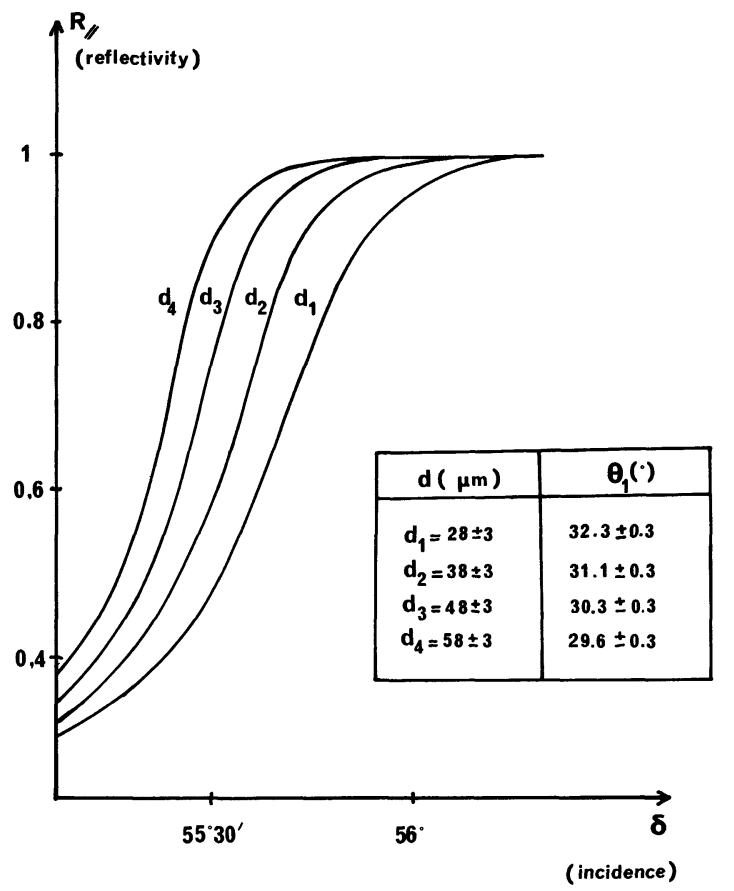

Fig. 3. - Experimental results : reflectivity $R_{\|}$versus incidence angle $\delta$ for different cell thickness and for parallel polarization.

$R_{\|} \sim 0.85$. This assumption is derived from computations relative to anisotropic and inhomogeneous media which we shall present in a forthcoming paper. On the other hand, we note that the variation of $\theta_{1}$ as a function of $1 / d$ is linear, thus confirming the validity of our method. Another experiment performed with $\varphi_{1}=\varphi_{2}$ (similar treatment on the two surfaces) gave no important tilt angle variation.

To obtain the anchoring energy at our substrate it is convenient to take the two extreme measurements $\theta_{1}\left(d_{1}\right)$ and $\theta_{1}\left(d_{4}\right)$ corresponding to $d_{1}=28 \mu \mathrm{m}$ and $d_{4}=58 \mu \mathrm{m}$. It is not then necessary to know the easy axis orientation $\varphi_{1}$. Moreover, we assume $\Delta \varphi$ constant, a condition which is very nearly obtained in our experiment :

$$
\Delta \varphi=60 \pm 3^{\circ} .
$$

We can write :

$$
W_{1}=\frac{K \Delta \varphi}{2 \Delta \theta}\left(\frac{1}{d_{1}}-\frac{1}{d_{4}}\right)
$$

with : $\Delta \theta=\theta_{1}\left(d_{1}\right)-\theta_{1}\left(d_{4}\right)$.

Using the value $\Delta \theta=2.7 \pm 0.6^{\circ}$, and

$$
K=10^{-6} \text { dynes [10], [11] , }
$$

we have the final result :

$$
W_{1}=(2.1 \pm 0.8) \cdot 10^{-3} \mathrm{erg} / \mathrm{cm}^{2}
$$

These results prove the validity of our assumptions (strong anchoring) and their self-consistency.
3. Discussion. - The anchoring properties of liquid crystals in contact with a substrate are still unknown and only few experiments can determine anchoring energies. By studying the typical defects of mesophases (Bloch walls), it is possible to estimate the anchoring energy [12], [13]; for a substrate constituted of the product of degradation of heated paper on glass, Ryschenkow [14] found a low energy $\left(10^{-4} \mathrm{erg} / \mathrm{cm}^{2}\right)$. Similar values have been obtained by Porte [5] with alignment induced by short chain surfactants. More recently, Naemura used wall effects in the Freedericks transition and gave an evaluation of the anchoring strength coefficients for different substrates and surfactants [7] : he found energy values spaced between $10^{-2}$ and $10^{-4} \mathrm{erg} / \mathrm{cm}^{2}$. Another method; used by Sicart [15], consists in applying a magnetic field to a twisted nematic cell : the measurement of the director rotation allows a determination of the anchoring energy; the results approach $10^{-3} \mathrm{erg} / \mathrm{cm}^{2}$ for untreated glass plates.

The method we present now is useful for measurements of strong as well as weak anchoring energies; the results for an obliquely evaporated $\mathrm{SiO}$ substrate are similar to those obtained for other substrates and by other experiments : $W_{0} \sim 10^{-3} \mathrm{erg} / \mathrm{cm}^{2}$. The main interest of such a determination is the use of optical detection of very slight variations of the liquid crystal orientation not within the layer but in the vicinity of the boundary surface, and it is not necessary to use an external field (electric or magnetic) for the experiment. The calculation of the anchoring energy require a knowledge of the elastic constants of the liquid crystal (constants now well known for most of the nematic phases) and the ordinary and extraordinary refractive indices (determined from the critical angle measurements [1]).

In fact, we have supposed that the tilt angle variation within the layer was slow enough to assume that the classic properties of electromagnetic waves in total reflection are applicable; then the liquid crystal is considered as a uniaxial homogeneous medium over a thickness equal to the penetration depth of the evanescent wave in this medium. In the opposite case, the liquid crystal must be considered as an inhomogeneous medium. We have undertaken computations for the latter and preliminary results show that the earlier assumptions are reasonable.

4. Conclusion. - Many systematic studies remain to be done and the results obtained are not exhaustive. Other substrates could be analysed and it would be useful to observe, for example, the influence of different evaporation parameters for the $\mathrm{SiO}$ thin films. We could also detect possible inhomogeneities in the substrate and the presence of impurities in the liquid crystal. We think such experiments would 
contribute to a better understanding of the coupling mechanism between a liquid crystal and its solid substrate.
Acknowledgments. - The authors wish to thank M. Boix for her helpful assistance in the preparation of $\mathrm{SiO}$ layers.

\section{References}

[1] Rivière, D., Lévy, Y., IMBert, C., Opt. Commun. 25 (1978) 206.

[2] Lévy, Y., Rivière, D., ImberT, C., Boix, M., Opt. Commun. 26 (1978) 225.

[3] Oseen, C. W., Trans. Faraday Soc. 29 (1933) 883.

[4] Frank, F. C., Disc. Faraday Soc. 25 (1958) 19.

[5] Porte, G., J. Physique 37 (1976) 1245.

[6] KahN, F. J., Appl. Phys. Lett. 22 (1973) 386.

[7] Naemura, S., Appl. Phys. Lett. 33 (1978) 1.

[8] Raynes, E. P., Rowell, D. K., Shanks, I. A., Mol. Cryst. Liq. Cryst. 34 (1976) 105.
[9] Guyon, E., Pieranski, P., Boix, M., J. Physique 39 (1978) 99. [10] Karat, P. P., Madhusudana, N. V., Mol. Cryst. Liq. Cryst. 36 (1976) 51.

[11] Karat, P. P., Madhusudana, N. V., Mol. Cryst. Liq. Cryst. 40 (1977) 239.

[12] Williams, C., Vitek, V., Kléman, M., Solid State Commun. 12 (1973) 581.

[13] Williams, C., Kléman, M., Philos. Mag. 23 (1973) 721.

[14] Ryschenkow, G., Kléman, M., J. Chem. Phys. 64 (1976) 404.

[15] SiCART, J., J. Physique Lett. 37 (1976) 25. 